\title{
The application of tannin extract from Anogeissus leiocarpus plant as wood adhesives
}

\author{
U. REUBEN ${ }^{1 *}$, J.T. BARMINAS ${ }^{2}$, B.A. ALIYU ${ }^{1}$ and S.A. OSEMEAHON ${ }^{2}$ \\ ${ }^{I}$ Department of Science Laboratory Technology, Modibbo Adama University of Technology P.M.B. 2076, \\ Yola, Adamawa State, Nigeria. \\ ${ }^{2}$ Department of Chemistry, Modibbo Adama University of Technology. \\ P.M.B. 2076, Yola, Adamawa State, Nigeria. \\ *Corresponding author, E-mail: usakureuben5@gmail.com; Tel: +2348065488491
}

\begin{abstract}
This work reports the extraction and application of tannins as wood- adhesives from Anogeissus leiocarpus plant using water, acetone or a mixture of these as solvent. In terms of the quantity of extracts from polyphenolic extract of Anogeissus leiocarpus bark, water was the most effective solvent, followed sequentially by acetone and solvent mixture (90\% acetone and $10 \%$ water). The use of solvent mixture in tannin extraction yielded high tannin content. The poly condensation reaction of Anogeissus leiocarpus bark extract is influenced significantly by amount of formaldehyde $(9.0 \mathrm{ml})$, tannin $(2.5 \mathrm{~g})$, glycerol $(0.6 \mathrm{ml})$, cure temperature $80^{\circ} \mathrm{C}$, types and $\mathrm{pH} 7.5$ of the adhesive medium. Adhesive joint of significant bond strength were obtained from Anogeissus leiocarpus tannin adhesive. Prolonged cure periods particularly at elevated temperature have adverse effect on the strength properties of these joints, especially with wood- panels as substrates. Joint prepared with adhesive derived from these extracts were tested for strength properties.

(C) 2013 International Formulae Group. All rights reserved.
\end{abstract}

Keywords: Anogeissus leiocarpus, tannin, polycondensation, Formaldehyde, cure temperature.

\section{INTRODUCTION}

The prevailing viewpoint of the origin of terrestrial aquatic humic substance applied in industries for the alleviation of human misery, discovery of new products and substituents of conventional raw materials with unconventional compounds are very necessary (Bindu, 2001). Over the last four decades, phenolic resins have been derived largely from petroleum, a finite, natural resources and other conventional sources which have contributed to the recent increase in the price of petroleum products. This led to the general rise in the prices of services and goods resulting in a fall in the value of money to the detriment of poor people.

Generally, the word adhesive used for is a substance used for sticking two bodies together, due to the molecular force existing in the area of contact (Hemingway et al., 1996). In practice, however, adhesive implies the broad set of materials composed of only organic components, mainly polymeric which can be used to fasten two materials together. The materials being fastened together by the adhesives are the adherands and the adhesive 
joint of adhesive bond is the resulting assembly. The words glue mucilage; mastic and cement are synonymous with adhesives (Sowumi et al., 2000). The fact that adhesives are used at critical points in various design situation, emphasis the requirement that adhesive bond must retain adequate strength throughout the life of structures involved under conditions of application or uses e.g. vibration, sustained loading, fluctuating temperature, in certain circumstances contract with fluid (Brune, 1990). The major property of this tannin formaldehyde adhesive is that it is the moset in nature, once cured; this part cannot be changed or reformed, except for finishing (Heinze, 1998). However, these resins become hardened by the use of heat and pressure due to the occurrence of threedimensional network structure. They cannot be softened by heating for the purpose of reprocessing. Some of the thermosetting resins which exhibit similar properties to tannin-formaldehyde adhesive includes expoxies, polyurethanes, phenolformaldehyde adhesives (Pizzi, 1985) etc.

Consequently, this research work is an attempt to extract tannin from Anogeissus leiocarpus bark and to develop adhesive tannin-formaldehyde from renewable and infinite resources i.e. the polyphenolic tannins extract from Anogeissus leiocarpus. This innovation may solve the problem of using petroleum-based resources; since the major components obtained are renewable and locally available.

\section{MATERIALS AND METHODS Materials}

The bark of Anogeissus leiocarpus plant which constitutes the primary raw materials was collected in Yola, Adamawa State of Nigeria. Formaldehyde, glycerol, acetone, sodium hydroxide and hydrochloric acid were purchased from British Drug House (BDH). In addition to these chemicals, laboratory apparatus were made used off, including; election precision balance, water bath, spring balance, rotor evaporator, mortar and pestle, oven drier, sieve shaker, $\mathrm{pH}$ meter.

\section{Extraction of tannin}

The method of extraction of tannin from mangrove tree reported by Barminas and Osemeahon (2006) was adopted. $100 \mathrm{~g}$ of the prepared sample was placed in a $100 \mathrm{ml}$ beaker. $500 \mathrm{ml}$ of solvent, water was added and was agitated in a mechanical shaker. At the end of the extraction period, which varied from 1 to 3 days, the extracts were filtered using Bucher's flask with whatman No.1 filter paper. The same procedure was repeated for acetone solvent and solvent mixture $(90 \%$ acetone and $10 \%$ water). The filtrat (extract solution) was concentrated to about $50 \mathrm{ml}$ using Buchi rotor and water bath at temperature below $40{ }^{\circ} \mathrm{C}$ and placed in thermostated vacuum oven at $20{ }^{\circ} \mathrm{C} .3 \mathrm{~kg}$ of the total weight of sample dissolved in 15 litres of total solvent ( $1 \mathrm{~kg}$ of the sample extract in 5 litres of each solvent used). The percentage extract (tannin content) in their respective solvent types was determined following the procedure earlier used by Paris (1992). The extract was then obtained in gelled form and later in powder mass. The percentage by weight of sample extract was computed on the basis of the original airdried samples.

\section{Gelation times of Anogeissus Leiocarpus Tannin formaldehyde adhesives}

The polycondensation reaction between Anogeisussus Leiocarpus extract and formaldehyde under various reaction conditions were studied by observing the gelation time (Emmanuel, 1991). The gelation time was observed as the period elapsing until the resin could support a $22 \mathrm{~g}$ of ball bearing of $0.247 \mathrm{~mm}$ in diameter. The effects of the following variables on gelation time were considered.

\section{Type of solvent and $\mathrm{pH}$ of resin}

A known quantity $(4.5 \mathrm{~g})$ of extract was transferred into test tubes containing $4 \mathrm{ml}$ of water and $\mathrm{pH}$ was adjusted by adding value by adding $0.1 \mathrm{M} \mathrm{H}_{2} \mathrm{SO}_{4}$. The test tubes containing the solutions were then placed in a water bath maintained at $60{ }^{\mathrm{O}} \mathrm{C}$. Formaldehyde solution $(9.0 \mathrm{ml})$ based on the total content of solution 
was added after the solution had reached the desired temperature of $60{ }^{\circ} \mathrm{C}$. The gelation time was measured using 50\% aqueous ethanol instead of pure water as the solvent medium for the adhesive.

\section{Formaldehyde concentration}

A known amount (3.0 g) of samples of tannin extract was transferred into a boiling tube contains $4.0 \mathrm{ml}$ of water, were mixed followed by glycerol $(1.0 \mathrm{ml})$. The mixture was placed in a water bath maintained at temperature of $40{ }^{\circ} \mathrm{C}$. The samples were all maintained at $\mathrm{pH}$ of 5.5 by the addition of 0.1 $\mathrm{M} \mathrm{NaOH}$. Different amount of formaldehyde (Ranging from 2.5 to $9.0 \mathrm{ml}$ ) relative to the mass of the total solids were also added after the solution had reached $60{ }^{\circ} \mathrm{C}$, and the gelation times were then measured.

\section{Reaction Temperature}

A known quantity of Anogeissus Leiocarpus bark extract $(3.5 \mathrm{~g})$ was transferred into $4.0 \mathrm{ml}$ of water in a test tube and mixed. This was placed in a water bath kept at well-defined temperatures $\left(20{ }^{\circ} \mathrm{C}, 40\right.$ ${ }^{0} \mathrm{C}, 60{ }^{0} \mathrm{C}$ and $70{ }^{0} \mathrm{C}$ ). The gelation times were measured at these temperatures. All the extract solutions were maintained at a $\mathrm{pH}$ of 5.5 and had a formaldehyde concentration of 9.0 (vol/vol) (Barminas and Osemeahon, 2006)

\section{Adhesive preparation (Tannin- formaldehyde adhesives) \\ Freshly prepared extract $(2.5 \mathrm{~g})$ was introduced into a test tube containing $2.5 \mathrm{ml}$ of the corresponding solvent used in the extraction. The test tube and its content were heated at $60{ }^{0} \mathrm{C}$ for 20 minutes in a water bath and then cooled for the adhesive to properly form from the extracts obtained with binary solvent mixtures. Glycerol $0.6 \mathrm{ml}$ was added to the mixture and was adjusted to $\mathrm{pH}$ 7.5 with $0.1 \mathrm{ml} \mathrm{NaOH}$. Formaldehyde was then added and the content of the test tube was mixed thoroughly.}

\section{Bonding method or (Joint Frame)}

The adherent (wood surface) of dimensions $12.5 \mathrm{~cm} \times 3.5 \mathrm{~cm} \times 2 \mathrm{~cm}$ was prepared, after which the adhesive was then applied finally by using a brush on the surface (open and closed assembly).The cure times were observed at 10 and 7 minutes respectively. The test samples were of simple lap joint type with a $7 \mathrm{~cm}$ overlap.

\section{Adhesive curing and fracture test (bond strength)}

Adhesive joints formed as described above were cured for various lengths of times (2-16 h). Curing was carried out at various temperature $\left(10-80{ }^{\circ} \mathrm{C}\right)$ using water baths. In the case of adhesives joint derived from extracts obtained from the various solvent mixtures, curing was done at $80{ }^{\circ} \mathrm{C}$ for 3 hours due to the relative low percentage extract (tannin content) compared to single solvent extraction and therefore resulted to the low interaction between the active reacting particle of tannin with the molecule of formaldehyde (poly condensation). All the samples bond strength were also tested using instron machine of 25 tons capacity.

For comparative purposes, some bonded joint samples were boiled in hot water for $1 \mathrm{~h}$, some were heated at temperature above the curing temperature while some were mechanically agitated before fracture tests were carried out. These comprised of wet and dry test. The dry test was purely mechanically and thermally while the wet involved boiling.

\section{RESULTS}

\section{Solvent type}

The effect of duration of cold extraction with pure solvents of water and acetone on the quality of extractable materials is illustrated in Figure 1. The relative effectiveness of the solvents in the extraction observed high in water, followed by acetone and then solvent mixture. The graph of water extracts, however, showed a maximum after the $8^{\text {th }}$ hour of extraction. The steeply decrease in the amount of extract after the maximum was more drastic for water than acetone. The corresponding plot for extraction with acetone increases rapidly at $5.8 \mathrm{~g}$ of 
tannin content after also the $8^{\text {th }}$ hour of extraction (Table 1).

\section{Tannin content}

Throughout the period of extraction, the tannin content was highest for acetone extraction (at maximum of $70 \%$ ) and appears constant for the subsequent duration followed by water (at maximum $30 \%$ ) as shown in Figure 2. Thus even though acetone extractable materials were least in quantity, acetone was decidedly most specific for tannin extraction Table 2.

Reactivity of Anogeissus Leiocarpus bark extract adhesive

pH medium of the resin

The dependence of the reactivity of Anogeissus leiocarpus bark extract, adhesive towards formaldehyde on the type and $\mathrm{pH}$ of medium is illustrated in Figure 3. It could be observed that the highest reactivity occurred at low $\mathrm{pH}$ and moderately alkaline condition.. From the $\mathrm{pH}$ values considered in the experiments, minimum reactivity i.e. longest gelation time occurred at about $\mathrm{pH} 7.5$. It is also observable from Figure 3, that change of medium from purely aqueous to aqueous ethanol resulted in a retardation of the reaction of Anogeissus leiocarpus bark extract adhesive (Table 3).
Effect of Temperature on Gelation Time for Tannin Adhesive from Aneogeissus leiocarpus

Gelation time decreased very rapidly with cure temperature about 1 hour, 40 minutes at ambient temperature to less than 1 $\mathrm{h}$ at temperature equal to or greater than $70{ }^{\circ} \mathrm{C}$ as shown in Figure 4.

\section{Test of bond strength}

Both cure temperature and cure time were varied to determine their effect on the resultant adhesives bond strength of simple lap joint with plywood as substrates. Dry and wet shear strength test were carried out. A typical result is given in Figure 5 for dry tests on the adhesives cured at $80{ }^{\circ} \mathrm{C}$. It however compares the results for dry test on the resins cured at different temperature. At a particular cure temperature, prolonged cure periods resulted in a drop in bond strength for both wet and dry test adhesives. The values of the maximum bond strength and the cure time at which the maximum occurred were highest for the dry test resins and then for the corresponding wet test adhesive. Very high cure temperatures did not necessarily results in adhesives joints with the highest bond strength.

Table 1: The effect of duration of cold extraction with single solvent on quantity of total extractable material.

\begin{tabular}{ccc}
\hline $\begin{array}{c}\text { Duration of extraction } \\
\text { (hour) }\end{array}$ & Water extract (g) & Acetone extract (g) \\
\hline 2 & 3.5 & 4.5 \\
4 & 5.5 & 5.2 \\
6 & 6.0 & 5.6 \\
8 & 7.3 & 5.8 \\
10 & 5.7 & 5.8 \\
12 & 4.6 & 5.2 \\
14 & 4.3 & 4.3 \\
16 & 4.1 & 3.4 \\
\hline
\end{tabular}


Table 2: Tannin content of the total extractions of bark with two different solvent.

\begin{tabular}{ccc}
\hline Duration (hours) & Water tannin content (\%) & Acetone tannin content $(\%)$ \\
\hline 2 & 10 & 37 \\
4 & 24 & 50 \\
6 & 33 & 59 \\
8 & 30 & 65 \\
10 & 30 & 70 \\
12 & 18 & 70 \\
14 & 18 & 70 \\
16 & 18 & 70 \\
\hline
\end{tabular}

Table 3: Effect of solvent and $\mathrm{pH}$ (water ethanol) 50\% solvent and 100\% water\$.

\begin{tabular}{ccccc}
\hline pH & $\begin{array}{c}\text { Formaldehyde Conc. } \\
\text { (vol/vol) }\end{array}$ & $\begin{array}{c}\text { Hexamine } \\
\text { Conc. }(\mathbf{g} / \mathbf{g}) .\end{array}$ & $\begin{array}{c}\text { Gelation time }{ }^{\circledR} \\
\text { (seconds) }\end{array}$ & Gelation \$ (second) \\
\hline 1.5 & 10.5 & 3.0 & 150 & 75 \\
2.5 & 10.5 & 3.0 & 200 & 115 \\
3.5 & 10.5 & 3.0 & 255 & 160 \\
4.5 & 10.5 & 3.0 & 320 & 205 \\
5.5 & 10.5 & 3.0 & 325 & 255 \\
6.5 & 10.5 & 3.0 & 440 & 305 \\
7.5 & 10.5 & 3.0 & 500 & 350 \\
8.5 & 10.5 & 3.0 & 235 & 125 \\
9.5 & 10.5 & 3.0 & 100 & 100 \\
10.5 & 10.5 & 3.0 & 85 & 70 \\
\hline
\end{tabular}

Table 4: The effect of formaldehyde concentration on gelation time of tannin extract of bark.

\begin{tabular}{cc}
\hline $\begin{array}{c}\text { Gelation time } \\
\text { (minutes) }\end{array}$ & $\begin{array}{c}\text { Formaldehyde contraction } \\
\text { (vol/vol) }\end{array}$ \\
\hline 1 & 17 \\
2 & 15 \\
3 & 8 \\
4 & 7 \\
5 & 6 \\
6 & 6 \\
7 & 6 \\
8 & 6 \\
\hline
\end{tabular}


Table 5: Effect of temperature on gelation time for the tannin adhesives.

\begin{tabular}{cc}
\hline Gelation time (hour) & Temperature $\left({ }^{\mathbf{0}} \mathbf{C}\right)$ \\
\hline 8.0 & 10 \\
4.5 & 20 \\
2.5 & 30 \\
2.0 & 40 \\
1.5 & 50 \\
1.4 & 60 \\
1.3 & 70 \\
1.0 & 80 \\
\hline
\end{tabular}

Table 6: Variation of bond strength. substrates bonded with adhesive from the tannins of Anogeissus leiocarpius bark on curing at $80{ }^{\circ} \mathrm{C}$.

\begin{tabular}{ccc}
\hline Cure time (hour) & \multicolumn{2}{c}{ Bond strength $\left.\mathbf{( N M}^{-\mathbf{2}}\right)$} \\
\cline { 2 - 3 } & Dry & Wet \\
\hline 2 & 8 & 14 \\
4 & 15 & 24 \\
6 & 22 & 30 \\
8 & 28 & 22 \\
10 & 34 & 12 \\
12 & 38 & 11 \\
14 & 27 & 10 \\
16 & 25 & 10 \\
\hline
\end{tabular}

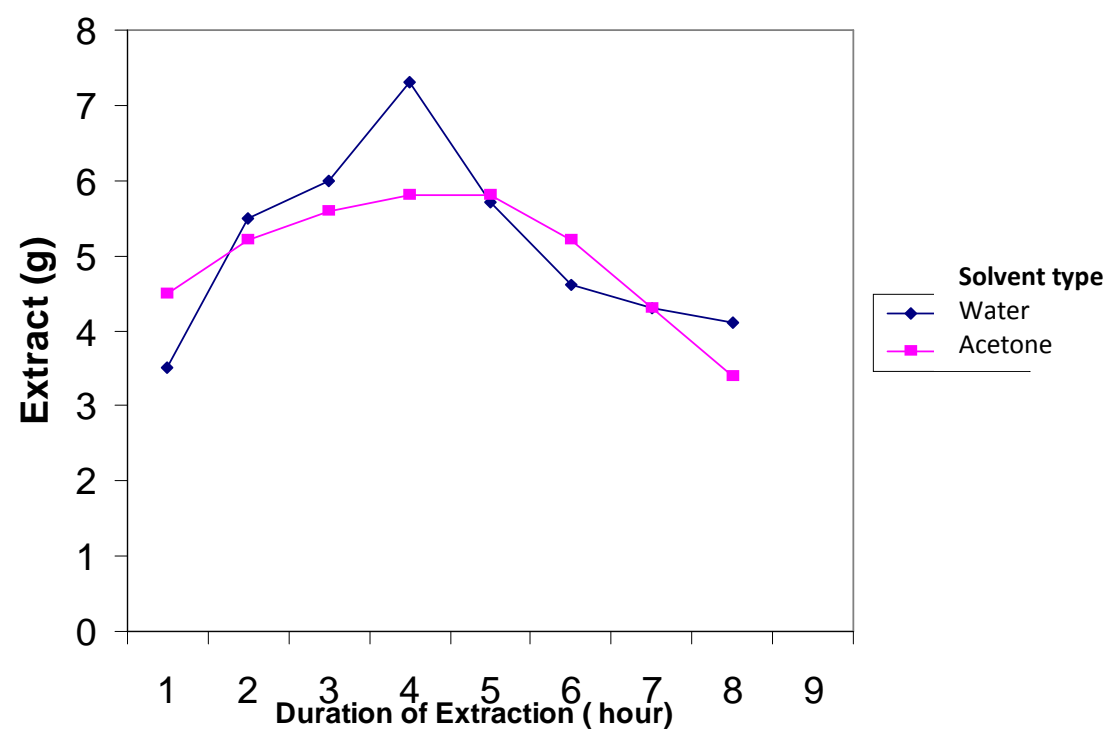

Figure 1: The effect of duration of cold extraction with single solvent on quantity of total extractable material. 


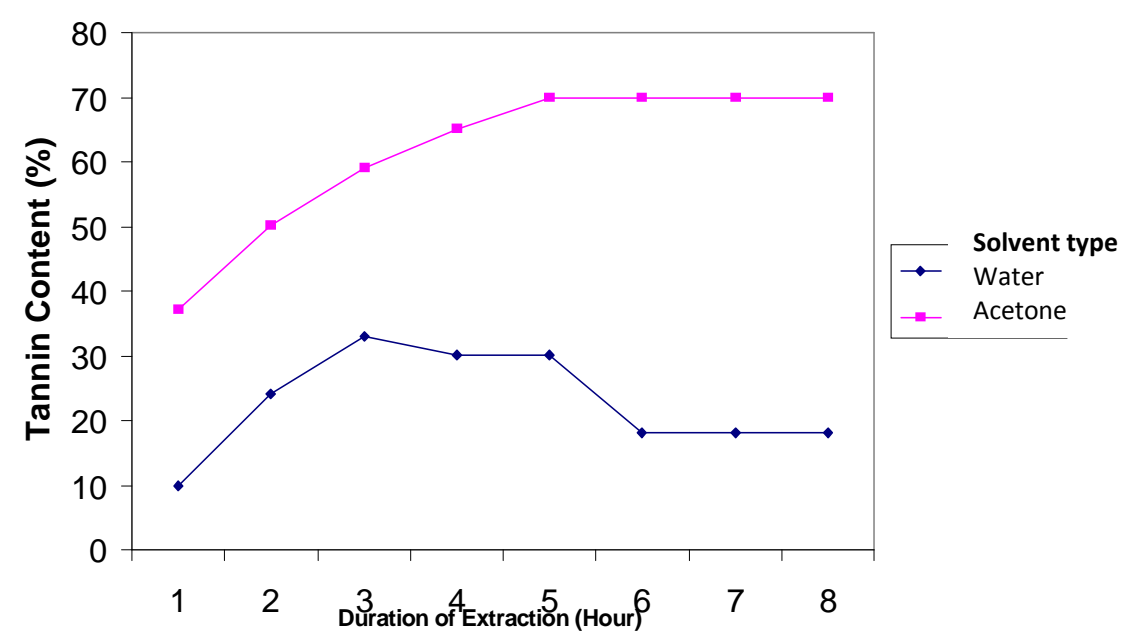

Figure 2: Tannin content of the total extracts of bark with two different solvents.

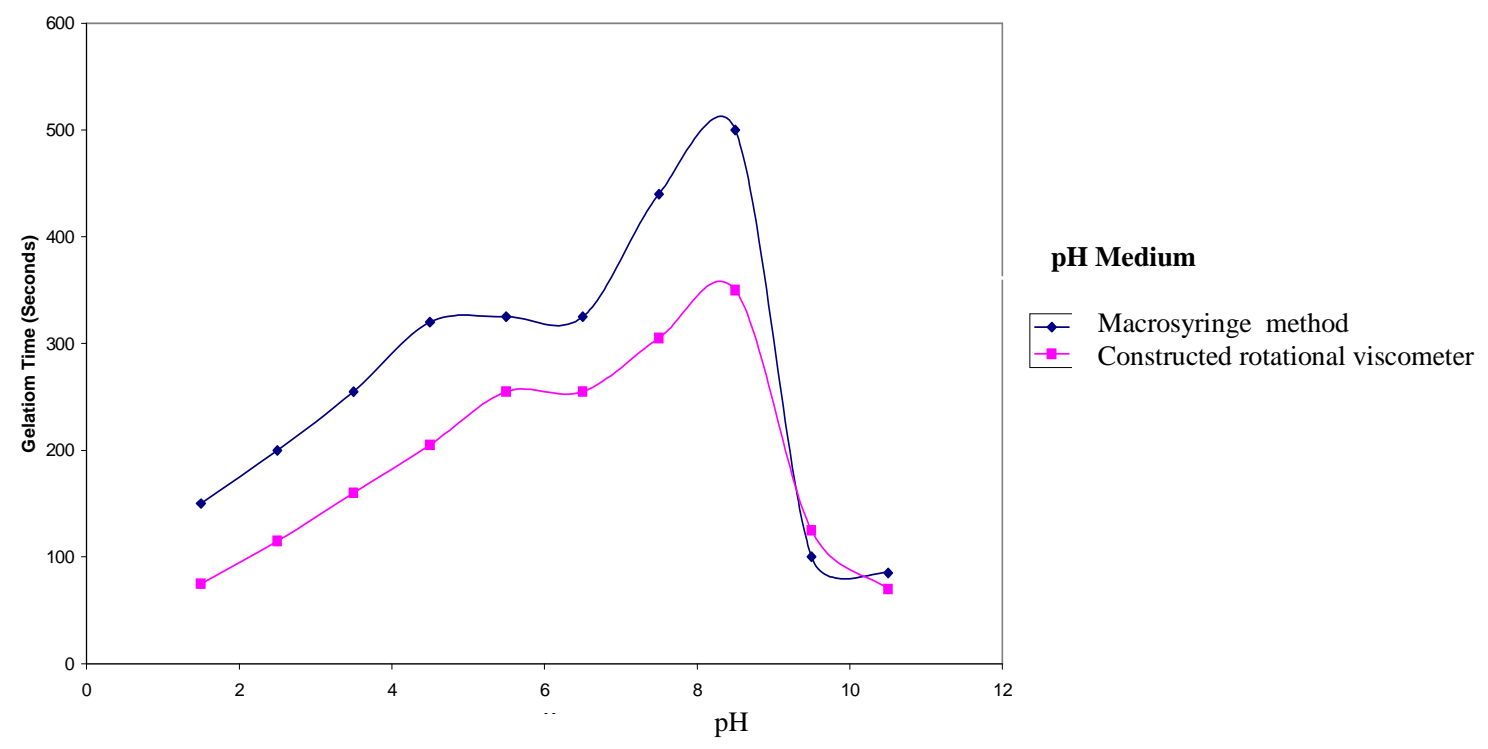

Figure 3: Effect of $\mathrm{pH}$ medium on the resin. 


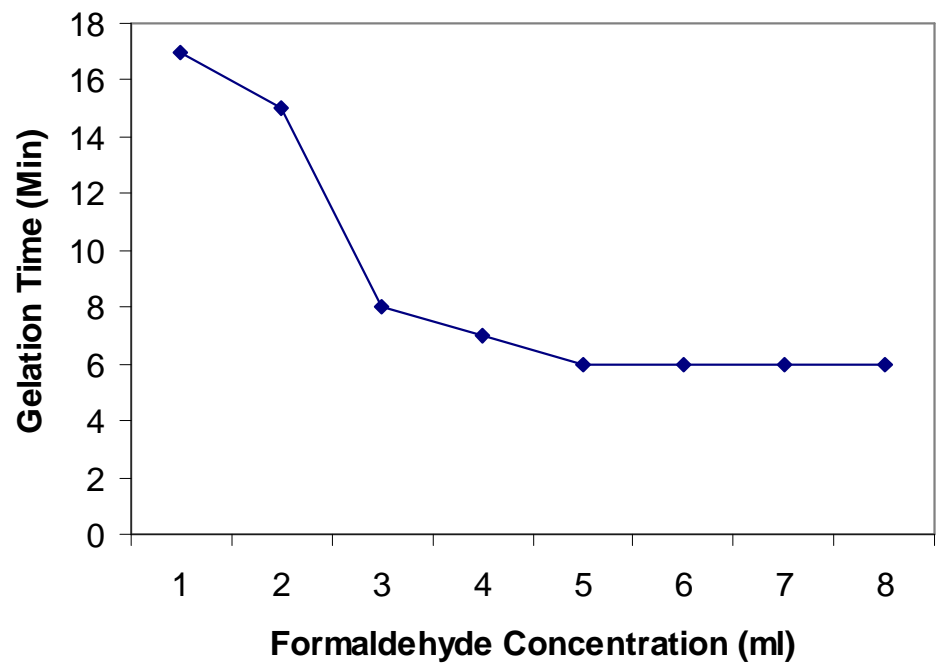

Figure 4: Effect of formaldehyde on gelation time of a tannin extract of bark.

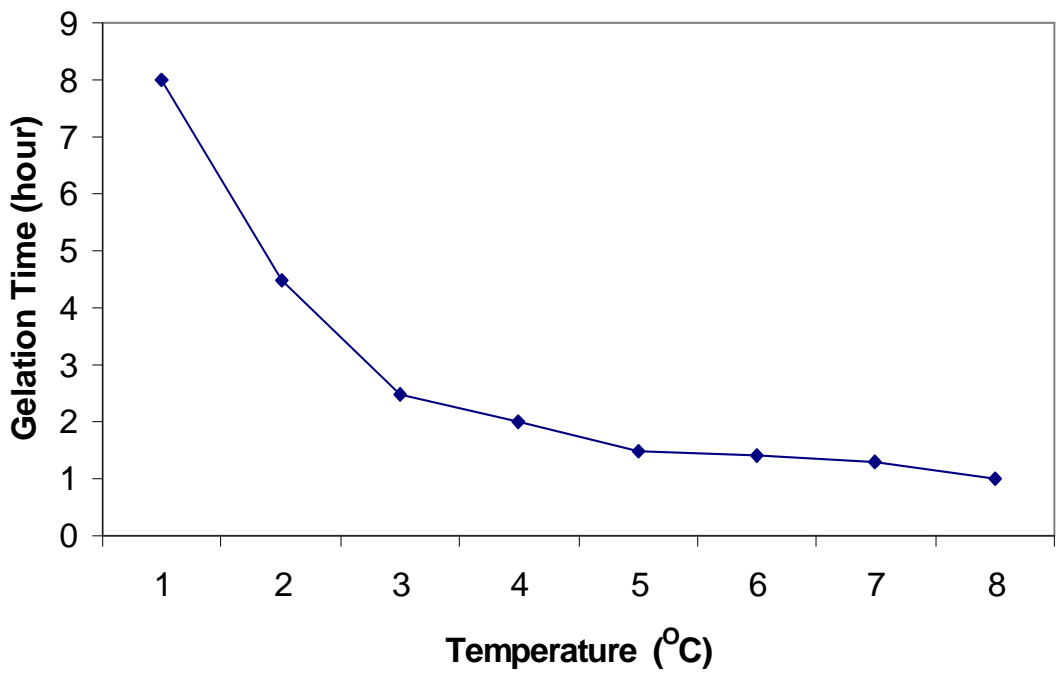

Figure 5: Effect of temperature on gelation time for the tannin adhesives. 


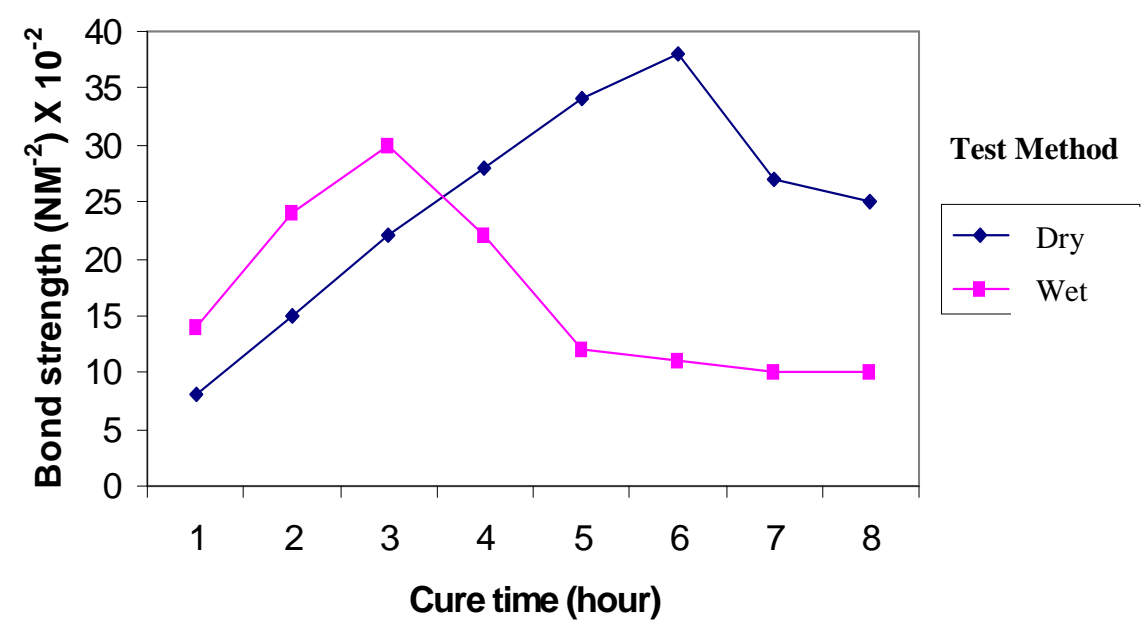

Figure 6: Effect of bond strength substrates bonded with adhesive from the tannin of Anogeissus leiocarpus bark on curing at $80{ }^{\circ} \mathrm{C}$.

\section{DISCUSSION}

Figure 1 shows the effect of duration of cold extraction of tannin content with pure solvents of water and acetone on the quality of extractable materials. The relative effectiveness of the solvents in the extraction was observed high in water, followed by acetone and then solvent mixture. The downward trend in the amount of extract after the maximum of $8^{\text {th }}$ hour of extraction was more drastic for water compare to acetone. The corresponding plot for extraction with acetone increases rapidly at $5.8 \mathrm{~g}$ of tannin content after also the $8^{\text {th }}$ hour of extraction.

Figure 2 explain the period of extraction relatively to tannin content of this plant species (Anogeissus leiocarpus). The highest tannin content obtained in acetone extraction was maximally at $70 \%$ and appears constant for the subsequent duration in water which minimally at 30\%. Even though acetone extractable materials were least in quantity explained by Heinze (1998). Acetone was decidedly, the most specific for tannin extraction.

Figure 3 is a typical plot showing the effective dependence of reactivity of Anogeissus leiocarpus bark extract towards formaldehyde on the type and $\mathrm{pH}$ of medium to form adhesives. It could be observed that the highest reactivity occurred at low $\mathrm{pH}$ and moderately alkaline condition. From the $\mathrm{pH}$ values considered in the experiments, minimum reactivity i.e. longest gelation time occurred at about pH 7.5. It is also observable in the trend that the change of medium from purely aqueous to aqueous ethanol resulted in a retardation of the reaction of Anogeissus leiocarpus bark extract adhesive. The reaction could contribute to the solid state morphology and physical properties of the adhesives as reported by Barminas and Osemeahon (2006)

Gelation time decreased very rapidly with cure temperature to about 1 hour, 40 minutes at ambient temperature to less than 1 $\mathrm{h}$ at temperature equal to or greater than $70{ }^{\circ} \mathrm{C}$ as shown in Figure 4. This type of result can be explained on the basis of the segmental factor of the resin (Afoakwa et al., 2002).

Tensile properties (tensile strength and elongation at break) were measured as described by Osemeahon et al. (2007). Both cure temperature and cure time were varied to determine their effect on the resultant adhesives bond strength of a simple lap joint with plywood as substrates. Dry and wet shear strength test were carried out. A typical result is given in Figure 5 for dry tests on the adhesives cured at $80{ }^{\circ} \mathrm{C}$. However, compares the results for dry test on the resins cured at different temperature. At a particular cure temperature, prolonged cure periods resulted in a drop in bond strength for both wet and dry test adhesives. The values of the maximum bond strength and the cure time at which the maximum occurred were highest for the dry test resins and then for the 
corresponding wet test adhesive. Very high cure temperatures did not necessarily results in adhesives joints with the highest bond strength.

\section{Conclusion}

This research work reveals that Anogeissus leiocarpus plant would yield effective tannin- phenolic formaldehyde resin. The research work also provided a platform for small scale thermosetting industry i.e wood- adhesives, which will serve as a basis for exploitation of other resin potentials of Nigeria's rich forest.

The $\mathrm{pH}$ type for different solvents, formaldehyde concentration and cure temperature were observed to have considerable influenced on the reactivity of Anogeissues leisocarpus bark extracts. Similarly, the longest gelation time was observed both in aqueous and mixture of water and acetone medium occurred at about $\mathrm{pH}$ 7.5. Prolonged cure periods particularly at elevated temperature have adverse effect on the strength properties of joint, especially with wood- panels as substrates. Joint prepared with adhesive derived from these extracts were tested for strength properties.

\section{REFERENCES}

Afoakwa EO, Sefa-Dedeh S. 2002. Viscoelastic properties and changes in pasting characteristics oftrifoliate yam (Dioscorea dumetorum) starch after harvest. Food Chem., 77: 203-208.

Barminas JT, Osemeahon SA. 2006. Development of amino resins for paint formulation. 11. Effect of temperature on new synthetic route. European Journal of Scientific Research, 14: 489-499.

Barminas JT, Osemeahon SA. 2006. Development of amino resins for paint formulation.11. Effect of temperature on new synthetic route. European Journal of Scientific. Reaarch, 14: 489-499.

Brune M, Rossander L, Holberg L. 1992. Iron absorption and phenolic Compounds; importance of difference phenolic structures, European Journal of Clinical Nutrition, 43: 547-549.

Emmanuel Y. 1991. Study of adhesive properties of urea formaldehyde and effect of additive. B. Tech. thesis, Department of Chemistry, FUT- Yola.

Heinze T. 1998. New ionic polymer by cellulose functionalization. Macromol. Chem. Physic., 199: 2341-2364.

Hemingway M, Laks, Richard W. 1996 Condensed tannins structure of the phenolic acids. Publication Information Holxforschung, 41: 287-292.

Hollman PC. 2005. Polyphenol and disease risk in epidemiologic studies. American Journal Clinical Nutrition, 4(6): 8-10.

Mark HM. 1987: Encyclopedia of Polymer Science and Engineering. John Willy and Sons Inc: NY; 35-38.

Paris L. 1992 Comparative investigation of thermosetting Adhesive properties of phenol-formaldehyde and Ureaformaldehyde Resin. B. Tech. Thesis, Department of Chemistry, FUT Yola, p. 9-10.

Pizz A. 1985. Wood Adhesive Chemistry and Technology. Marcel Becker, Inc.: New York; 19-21.

Wilson E. 1991. Study of adhesive properties of urea formaldehyde and effect of additive B. Tech thesis, Department of Chemistry, ATBU Bauchi. 